\title{
Photosynthetic, physiological and biochemical events associated with polyethylene glycol-mediated osmotic stress tolerance in taro (Colocasia esculenta L. Schott)
}

\author{
M.R. SAHOO ${ }^{*, * * \#+}$, M. DASGUPTA ${ }^{*, * *, \#, ~ P . C . ~ K O L E ~}{ }^{* * *}$, and A. MUKHERJEE ${ }^{* * * *}$ \\ ICAR Research Complex for NEH Region, Lamphelpat, Imphal, Manipur, 795004, India* \\ University of Tennessee, Knoxville, TN, 37996, USA ${ }^{* *}$ \\ Department of Crop Improvement, Horticulture and Agricultural Botany, Institute of Agriculture, \\ Visva Bharati, Sriniketan, West Bengal, 731236, India ${ }^{* * *}$ \\ Regional Centre of Central Tuber Crops Research Institute, Bhubaneswar, Odisha, 751019, India ${ }^{* * * *}$
}

\begin{abstract}
Six genotypes of taro (Colocasia esculenta L. Schott) were evaluated under in vitro and in vivo polyethylene glycol (PEG6000)-mediated osmotic stress conditions. A significant variation in growth response was observed among the taro genotypes under in vitro-induced stress conditions. In vivo results indicated a significant effect of osmotic stress on photosynthetic parameters, such as net photosynthetic rate, transpiration rate, stomatal conductance, stomatal resistance, internal $\mathrm{CO}_{2}$ concentration, carboxylation efficiency, and transpiration efficiency on the tested genotypes at the tuberization stage. Lesser variations in photosynthesis and higher accumulation of proline, phenols, and antioxidative enzymes, namely, superoxide dismutase and guaiacol peroxidase, were associated with yield maintenance under osmotic stress conditions. The genotypes DP-89, IGCOL -4 , and Ramhipur showed a higher degree of tolerance towards osmotic stress with a minimum variation in the studied parameters. These genotypes could be lines of interest for intensification of breeding strategies to develop drought-tolerant plants.
\end{abstract}

Additional key words: antioxidative enzymes; osmotic stress; photosynthesis; physiology; polyethylene glycol; taro.

\section{Introduction}

Osmotic stress triggers a broad range of plant responses, which affect many physiological and biochemical events (Flexas et al. 2002), cellular and molecular processes (Muscolo et al. 2015) and leads to a yield reduction (Ramírez et al. 2015). To mitigate the adverse effects of osmotic stress, plants undergo various changes involving a mixture of stress tolerance and avoidance mechanisms (Yue et al. 2006). The tolerance strategies involve immediate physiological and biochemical responses (Sourour et al. 2017), whereas the avoidance mechanisms are associated with the morphological adaptations (Blum 2005). A better understanding of the tolerance behavior at physiological and biochemical level (Li and Liu 2016) leads to identification of genotypes which could well adapt to water deficit and maintain growth and development during stress period (Chandra et al. 2004). An earlier exposure to stress at tissue or cellular level enhances plant's tolerance to later abiotic insult (Chen and Arora 2013) which is considered as acclimatization (Chen et al. 2012) or plant priming ( $\mathrm{Li}$ et al. 2015). Hence, in vitro stress induction studies offer a meaningful tool for understanding stress tolerance in tuber crops (Dasgupta et al. 2008). However, rigorous screening and evaluation under in vivo-induced stress conditions and understanding

\footnotetext{
Received 3 June 2017, accepted 19 October 2017, published as online-first 13 April 2018.

${ }^{+}$Corresponding author; e-mail: manas.sahoo@icar.gov.in

Abbreviations: $\mathrm{BA}$ - 6-benzyladenine; $C_{\mathrm{i}}$ - intercellular $\mathrm{CO}_{2}$ concentration; $\mathrm{CE}$ - carboxylation efficiency; Chl - chlorophyll; CSI chlorophyll stability index; $E$ - transpiration rate; EDTA - ethylene diamine tetraacetic acid; $\mathrm{GA}_{3}$ - gibberellic acid; GPX - guaiacol peroxidase; $g_{s}$ - stomatal conductance; NAA - $\alpha$-naphthalene acetic acid; NBT - nitroblue tetrazolium; PAGE - polyacrylamide gel electrophoresis; $P_{\mathrm{N}}$ - photosynthetic rate; ROS - reactive oxygen species; RS - reducing sugar; $R_{\mathrm{S}}$ - stomatal resistance; RWC - relative water content; SOD - superoxide dismutase; TE - transpiration efficiency; TSS - total soluble sugar.

Acknowledgements: The work was supported by Indian Council of Agricultural Research, New Delhi, India. The authors are also thankful to the Director and Head, Central Tuber Crops Research Institute, Regional Centre, Bhubaneswar, India for infrastructure facilities.

\#These authors contributed equally to this work.
} 
induced-tolerance mechanisms confer long-term adaptation to harsh environments.

Taro [Colocasia esculenta (L.) Schott] is one of the important food crops in the developing world and considered to be a climate resilient crop. Its edible corms are a rich source of carbohydrates and minerals, adding immense commercial value to this crop. Production of taro often threatened by water scarcity leads to $90 \%$ of yield loss to total crop failure (Ravi and Chowdhury 1997). The major factor limiting taro growth is the amount of soil moisture available to the crop during the growing season. The unavailability of water at a tuberization stage results in a tuber yield reduction (Sunitha et al. 2013) as a cumulative effect of reduced leaf area, dry matter production, and some physiological parameters (Ravi and Chowdhury 1997, Mabhaudhi et al. 2013). An understanding of the genetic architecture of drought tolerance components would be an important milestone for breeding advancement (Obidiegwu et al. 2015).

Elevated leaf area, chlorophyll (Chl) content, relative water content (RWC), net photosynthetic rate, and subsequently an increase in proline concentrations are key indices for osmotic stress tolerance (Luo et al. 2016). Osmotic stress also triggers rapid accumulation of reactive

\section{Materials and methods}

Study site and plant materials: Six genotypes of taro comprising of three tolerant (DP-89, IGCOL-4, and Ramhipur), two moderately tolerant (DP-25 and Jhankri), and one susceptible (Hunger Local) were selected from a wide genetic base of 172 genotypes showing various degree of tolerance to osmotic stress (Sahoo et al. 2006a). This study was undertaken at the Regional Centre of Central Tuber Crops Research Institute (RCCTCRI), Bhubaneswar $\left(20^{\circ} 15^{\prime} \mathrm{N}\right.$ latitude, $85^{\circ} 52^{\prime} \mathrm{E}$ longitude, and altitude of $26 \mathrm{~m}$ a. s. 1.), India. The climatic condition of the place is warm and moist, with hot summer and mild winter.

In vitro culture medium, culture conditions and observations: Selected genotypes were raised in vitro through cormel tip cultures under MS (Murashige and Skoog 1962) media supplemented with plant growth regulators, i.e., $\alpha-$ naphthalene acetic acid (NAA, $2.7 \mu \mathrm{M}$ ), 6-benzyladenine (BA, $4.4 \mu \mathrm{M})$, and gibberellic acid $\left(\mathrm{GA}_{3}\right.$, $1.45 \mu \mathrm{M})$ (Dasgupta et al. 2008). The MS media with above mentioned growth regulators and $3 \%$ sucrose were used as the control. In order to induce osmotic stress $(-0.2 \mathrm{MPa})$, the same media were supplemented with PEG-6000 (118.0 $\left.\mathrm{g} \mathrm{L}^{-1}\right)$ prior to $\mathrm{pH}$ adjustment $(5.7 \pm 1)$ and dissolved in $0.8 \%$ Difco-Bacto agar (Hi-Media, India). The medium was sterilized at $105 \mathrm{kPa}$ for $15 \mathrm{~min}$ in a steam autoclave (REMI, India). Cormel tips $(5-10 \mathrm{~mm})$ of the six selected taro genotypes were surface-sterilized with $0.1 \%$ sodium hypochlorite (Merck, India) solution for 5-7 min, followed by thorough rinsing in sterile distilled water thrice and inoculated in the test tubes $(25 \times 100 \mathrm{~mm})$ oxygen species (ROS), which could be toxic to plants (Wei et al. 2015). Consequently, plants deploy a ROSscavenging system comprising of enzymatic and nonenzymatic antioxidants (Gill and Tuteja 2010). Information on photosynthetic changes, biochemical events and role of antioxidative enzymes in ROS scavenging is scanty for this nutrition-rich crop under polyethylene glycol (PEG)-mediated osmotic stress. Thus, there is a need to understand the physiological changes, photosynthetic and biochemical regulations, and ROS defense machineries in taro under induced stress conditions in order to develop a stress-tolerant line.

Keeping this in view, we studied the mechanisms adopted by six taro genotypes under in vitro and in vivo PEG-mediated osmotic stress conditions by investigating their morphological traits in terms of leaf area and physiological attributes [RWC, Chl stability index (CSI), and photosynthetic parameters]. We also reported the PEG-induced biochemical changes in taro leaves and the role of antioxidative enzymes, such as superoxide dismutase (SOD) and guaiacol peroxidase (GPX), and antioxidants, i.e., phenol content, in PEG-induced ROSscavenging mechanisms.

containing MS medium with or without PEG-6000. The cultures were maintained at $25 \pm 2{ }^{\circ} \mathrm{C}$ with $16 / 8$-h light/dark cycle and $45 \mu \mathrm{mol}$ (photon) $\mathrm{m}^{-2} \mathrm{~s}^{-1}$ illumination provided by cool/white fluorescence tubes (Phillips, India) with $55-60 \%$ relative humidity for six weeks. Each treatment included six replicates of each genotype and the experiment was carried out in $6 \times 2$ factors completely randomized design (CRD). In vitro growth responses, such as days to sprout, number of leaves, shoots and roots, the length of shoots and roots, were recorded after six weeks of growth.

In vivo experimental layout and observations: Six-weekold plantlets were acclimatized and maintained in the earthen pots $(30 \mathrm{~cm}$ in diameter) containing garden soil, sand, and farm yard manure $(1: 1: 1)$ under greenhouse [16-h photoperiod, $350 \mu \mathrm{mol}\left(\right.$ photon) $\mathrm{m}^{-2} \mathrm{~s}^{-1}$ light intensity, and temperature of $25 / 20^{\circ} \mathrm{C}$ day/night]. The pots were watered with PEG-6000 solutions $(0$ and $-0.2 \mathrm{MPa})$ at 2 -week interval to maintain the stress. This experiment was designed with the same six genotypes and two treatments of PEG stress, replicated thrice under $6 \times 2$ factorial CRD. Morphological, physiological, and biochemical parameters associated with stress tolerance were investigated at the crucial period of tuberization ( $45 \mathrm{~d}$ after planting).

Leaf area: The leaf area was calculated according to the linear measurement method as described by Biradar et al. (1978). The length and breadth of the leaf was multiplied by 0.917 to calculate the leaf area (leaf area $=$ length $\times$ breadth $\times 0.917)$. 
Relative water content (RWC) of the leaf was measured as an indicator of a leaf hydration status according to Perez et al. (2002). Fresh leaves were collected randomly from each replication and weighed (FM) immediately followed by submerging in distilled water for $4 \mathrm{~h}$ at $22^{\circ} \mathrm{C}$. The turgid mass (TM) was measured after blotting the submerged leaves and the dry mass (DM) was determined after the samples were dried for $72 \mathrm{~h}$ at $70^{\circ} \mathrm{C}$ in a hot air oven (Remi, India). The RWC was calculated as $\mathrm{RWC}=$ $[(\mathrm{FM}-\mathrm{DM}) /(\mathrm{TM}-\mathrm{DM})] \times 100$.

Chl stability index (CSI) is based on pigment changes induced by heating. The leaf samples were subjected to heat treatment by immersing in distilled water bath at $56^{\circ} \mathrm{C}$ for $30 \mathrm{~min}$. The $\mathrm{Chl}$ content in treated and control samples kept at room temperature was determined using a soil plant analytical development $(S P A D-502)$ portable leaf chlorophyll meter (Minolta Corp., Romsey, NJ). Three SPAD readings were taken on each of the leaves to obtain the average $\mathrm{Chl}$ content under each treatment and replications. CSI was calculated by the formula as described by Mohan et al. (2000), i.e., CSI $=[(\mathrm{Chl}$ content of treated samples/Chl content of control samples $) \times 100]$.

Photosynthetic measurements: All gas-exchange measurements, such as the net carbon assimilation rate/ photosynthetic rate $\left(P_{\mathrm{N}}\right)$, transpiration rate $(E)$, stomatal conductance $\left(g_{\mathrm{s}}\right)$, stomatal resistance $\left(R_{\mathrm{s}}\right)$, intercellular $\mathrm{CO}_{2}$ concentration $\left(C_{\mathrm{i}}\right)$, carboxylation efficiency $(\mathrm{CE}$, $\left.P_{\mathrm{N}} / C_{\mathrm{i}}\right)$, and transpiration efficiency (TE, $\left.P_{\mathrm{N}} / E\right)$, were determined between 11:00-13:00 $\mathrm{h}$ on the first fully expanded leaf using a portable open-system infrared gas analyzer (LCA-4, Analytical Development Co. Ltd., UK). The measurement light was maintained at about 800 $\mu$ mol(photon) $\mathrm{m}^{-2} \mathrm{~s}^{-1}$ at controlled $\mathrm{CO}_{2}$ concentration of $350 \pm 5 \mathrm{~cm}^{3} \mathrm{~m}^{-3}$. The chamber temperature ranged between $25 \pm 2{ }^{\circ} \mathrm{C}$ during the day time. Readings were logged until a stable reading was reached and each parameter was calculated from the average of three readings.

Biochemical estimations: The total leaf soluble protein content was measured by the protein dye-binding method of Bradford (1976) using bovine serum albumin (BSA) as standard. Total soluble sugar (TSS) and reducing sugar (RS) were quantified following the anthrone method as described by Roe (1955) and Nelson (1944), respectively, using glucose as standard. Proline content was estimated from the leaf extracts by following the standard protocol of Bates et al. (1973) and L-proline as standard.

Antioxidative enzyme assays, preparation of enzyme extracts and assay conditions: For the preparation of antioxidative enzyme extracts, the newly emerged fully expanded leaves (fresh mass of $250 \mathrm{mg}$ ) of taro genotypes were ground in liquid nitrogen to fine powder and were homogenized with $50 \mathrm{mM} \mathrm{NaPO}_{4}$ buffer (pH 7.8) containing $1 \mathrm{mM}$ EDTA, $0.1 \%$ Triton $X-100,1 \mathrm{mM}$ ascorbate, and $10 \%$ sorbitol. The homogenate was centrifuged at $15,000 \mathrm{rpm}$ at $4{ }^{\circ} \mathrm{C}$ for $20 \mathrm{~min}$ and the supernatant was used for the following enzyme assays. The total soluble protein concentrations were also determined by the spectrophotometric method of Bradford using BSA as the standard (Bradford 1976).

Superoxide dismutase (SOD, EC 1.15.1.1) activity was determined following Giannopolitis and Ries (1977), which is based on the ability to inhibit the photochemical reduction of nitroblue tetrazolium chloride (NBT). The reaction mixture $(4.0 \mathrm{ml})$ comprised of $50 \mathrm{mM}$ phosphate buffer ( $\mathrm{pH}$ 7.8), $0.1 \mu \mathrm{M}$ EDTA, $13 \mathrm{mM}$ methionine, $75 \mathrm{mM}$ NBT, $2 \mathrm{mM}$ riboflavin, and $0.2 \mu \mathrm{l}$ of enzyme extract. Riboflavin was added last and tubes were shaken and illuminated with two $20-\mathrm{W}$ fluorescent tubes. The reaction was allowed to proceed for 15 min after which the illuminating tubes were switched off and the tubes were covered with a black cloth. The absorbance of the reaction mixture was taken at $560 \mathrm{~nm}$. One unit of SOD activity (U) was defined as the amount of enzyme required for $50 \%$ inhibition of the NBT photoreduction rate and the results were expressed as unit per milligram of protein.

Guaiacol peroxidase (GPX, EC 1.11.1.7) activity was quantified as described by Urbanek et al. (1991) in a reaction mixture $(2.0 \mathrm{ml})$ containing $100 \mathrm{mM}$ phosphate buffer ( $\mathrm{pH}$ 7.0), 0.1 $\mu \mathrm{M}$ EDTA, $5.0 \mathrm{mM}$ guaiacol, $15.0 \mathrm{mM} \mathrm{H}_{2} \mathrm{O}_{2}$, and $50 \mu \mathrm{l}$ of enzyme extract. The increase in absorbance was recorded at an interval of $30 \mathrm{~s}$ for $3 \mathrm{~min}$ at $470 \mathrm{~nm}$. Enzyme activity was quantified by the amount of tetraguaiacol formed using its molar extinction coefficient $\left(26.6 \mathrm{mM}^{-1} \mathrm{~cm}^{-1}\right)$. All the spectrophotometric assays were performed using a UV-Vis spectrophotometer (Thermo Fischer Scientific, USA) at room temperature as described by Dasgupta et al. (2008).

The isoform profiles of SOD and GPX were examined by discontinuous native polyacrylamide gel electrophoresis (native PAGE, Laemmli 1970). Native PAGE was carried out by using 7.5\% separating gel containing $1.5 \mathrm{M}$ Tris buffer ( $\mathrm{pH}$ 8.8) and $4.5 \%$ stacking gel containing $0.5 \mathrm{M}$ Tris buffer ( $\mathrm{pH}$ 6.8). An equal amount of protein $(60 \mu \mathrm{g})$ from each extract was loaded along with sample loading dye (Tris, pH 6.8, 0.1\% bromophenol blue, and $15 \%$ glycerol) in the wells. The electrophoresis was carried out in the presence of Tris-glycine buffer $(25 \mathrm{mM}$ Tris, $\mathrm{pH} 8.3$, and $192 \mathrm{mM}$ glycine) at $20 \mathrm{~mA}$ constant current until the blue dye reached the bottom of the gel. Immediately after electrophoresis, staining activity was carried out by incubating the gel in substrate solution as described by Sahoo et al. (2007).

For the assay of phenol content, leaf samples of $0.5 \mathrm{~g}$ per replication per treatment were homogenized with $75 \%$ ethanol, shaken for $15 \mathrm{~min}$ at $70^{\circ} \mathrm{C}$, and the extract was centrifuged at $10,000 \mathrm{rpm}$ for $10 \mathrm{~min}$ in a cooling centrifuge (REMI, India). The supernatant was collected and used for the estimation of phenolics using FolinCiocalteau's method (Zieslin and Ben-Zaken 1993). A standard curve was generated with different concentrations 
of catechol (Hi Media, India) and was used to quantify the phenolics, which was expressed in milligrams of catechol produced per gram of leaf fresh mass.

Corm yield: Taro corms were harvested at $120 \mathrm{~d}$ after planting. The plant debris was removed from the corms and weighed to obtain the corm yield ( $g$ per plant). The pattern of stress tolerance was estimated based on the variations in the studied parameters under moisture stress as compared with control.

Statistical analysis: The experiments were conducted in

\section{Results}

Effect of PEG-mediated osmotic stress on growth responses of taro genotypes in vitro: The ANOVA (mean sum of square, MSS) for the growth parameters in vitro indicated a significant effect of PEG treatment on the tested genotypes (Table 1). The result revealed that the days to sprout decreased significantly under in vitro $\mathrm{PEG}$-mediated osmotic stress as compared with control (Fig. 1A). Days to sprout were delayed under PEG (14.3 d) as compared to stress-free control (5.4 d). Under osmotic stress, Ramhipur exhibited early sprouting $(11.7 \mathrm{~d})$ followed by Jhankri (12.2 d), and IGCOL-4 (12.7 d) (Fig. $1 A)$.

PEG-mediated osmotic stress had a significant detrimental effect on all the studied growth parameters, such as number of leaves, shoots and roots, length of shoots and roots. However, the significant genotypic variation was observed in all the parameters except of the number of leaves and roots (Table 1). The mean number of leaves varied from 2.0 to 2.3 in tested genotypes; and it was reduced to 1.0-2.0 under induced osmotic stress (Fig. 1B). Shoot emergence was also affected at $-0.2 \mathrm{MPa}$ stress; the mean number of shoots (Fig. 1C) and roots (Fig. 1D) per explant was less than 2 in all studied genotypes. After six weeks of cultivation, control taro plantlets attained the height of $4.5-6.25 \mathrm{~cm}$; it was reduced significantly to 3.10-5.02 cm under osmotic stress media (Fig. 1E).
$6 \times 2$ factorial $\mathrm{CRD}$ and the data were analysed statistically following the analysis of variance ( $A N O V A)$; significance was tested at probability level $P \leq 0.05$ and $P \leq 0.01$. Graphical representations are means of three replications with duplicate determinations. For the assay of antioxidant enzymes, repetition was performed twice within each replication. Tukey's test was performed to compare significant differences between the mean values (Tukey 1949). Yield reduction was correlated with the variations in photosynthesis, physiological, and biochemical properties under stress using Pearson's correlation coefficient ( $r$ values) at significance level $P \leq 0.05$ and $P \leq 0.01$.

The average root length also significantly decreased among the studied genotypes (Fig. $1 F$ ). The rate of decrease in length of the shoots and roots was lower in DP-25, IGCOL-4, Ramhipur, Jhankri, and DP-89, and higher in Hunger Local.

Effect of PEG on morphological and physiological properties of taro genotypes in vivo: The mean sum of squares (MSS) and their significance according to the twoway $A N O V A$ for six taro genotypes under in vivo PEGmediated osmotic stress are summarized in Table 2 . The $A N O V A$ for the studied parameters indicated significant effects of the genotypes, PEG stress, and genotypes $\times$ PEG stress interaction for all the studied parameters with an exception of transpiration rate $(E)$ and stomatal resistance $\left(R_{\mathrm{S}}\right)$. The result of the effect of PEG-6000-mediated osmotic stress on morphological and physiological properties of taro plants are represented in Fig. 2.

The leaf area ranged from 127.62 to $235.0 \mathrm{~cm}^{2}$ among the genotypes under controlled conditions, which was significantly reduced to 125.02 to $217.0 \mathrm{~cm}^{2}$ under stress (Fig. 2A). Although, IGCOL-4 had attained lower leaf area under both control and stress conditions, the rate of decrease in leaf area was lower in IGCOL-4 and higher in Hunger Local (Fig. 2A). RWC under control was ranged

Table 1. Two-way analysis of variance (mean sum of squares) for growth parameters of taro genotypes under in vitro PEG-mediated osmotic stress conditions in a $6 \times 2$ factorial experiment in a complete randomised design (CRD). ${ }^{*},{ }^{* *}$ and ${ }^{\mathrm{NS}}-P \leq 0.05, P \leq 0.01$, and $P>0.05$, respectively.

\begin{tabular}{|c|c|c|c|c|c|c|c|}
\hline Source & $d f$ & Time to sprout [d] & No. of leaves & No. of shoots & No. of roots & Shoot length & Root length \\
\hline Genotype & 5 & $26.91^{* *}$ & $0.78^{\mathrm{NS}}$ & $1.22^{* *}$ & $0.36^{\mathrm{NS}}$ & $6.26^{* *}$ & $0.20^{* *}$ \\
\hline PEG & 1 & $1395.68^{* *}$ & $3.13^{*}$ & $2.00^{*}$ & $1.68^{* *}$ & $38.28^{* *}$ & $22.67^{* *}$ \\
\hline Genotype $\times$ PEG & 5 & $15.25^{* *}$ & $0.29^{\mathrm{NS}}$ & $0.10^{\mathrm{NS}}$ & $0.18^{\mathrm{NS}}$ & $2.49^{*}$ & $0.18^{* *}$ \\
\hline Error & 60 & 4.28 & 0.51 & 0.41 & 0.21 & 0.96 & 0.04 \\
\hline
\end{tabular}




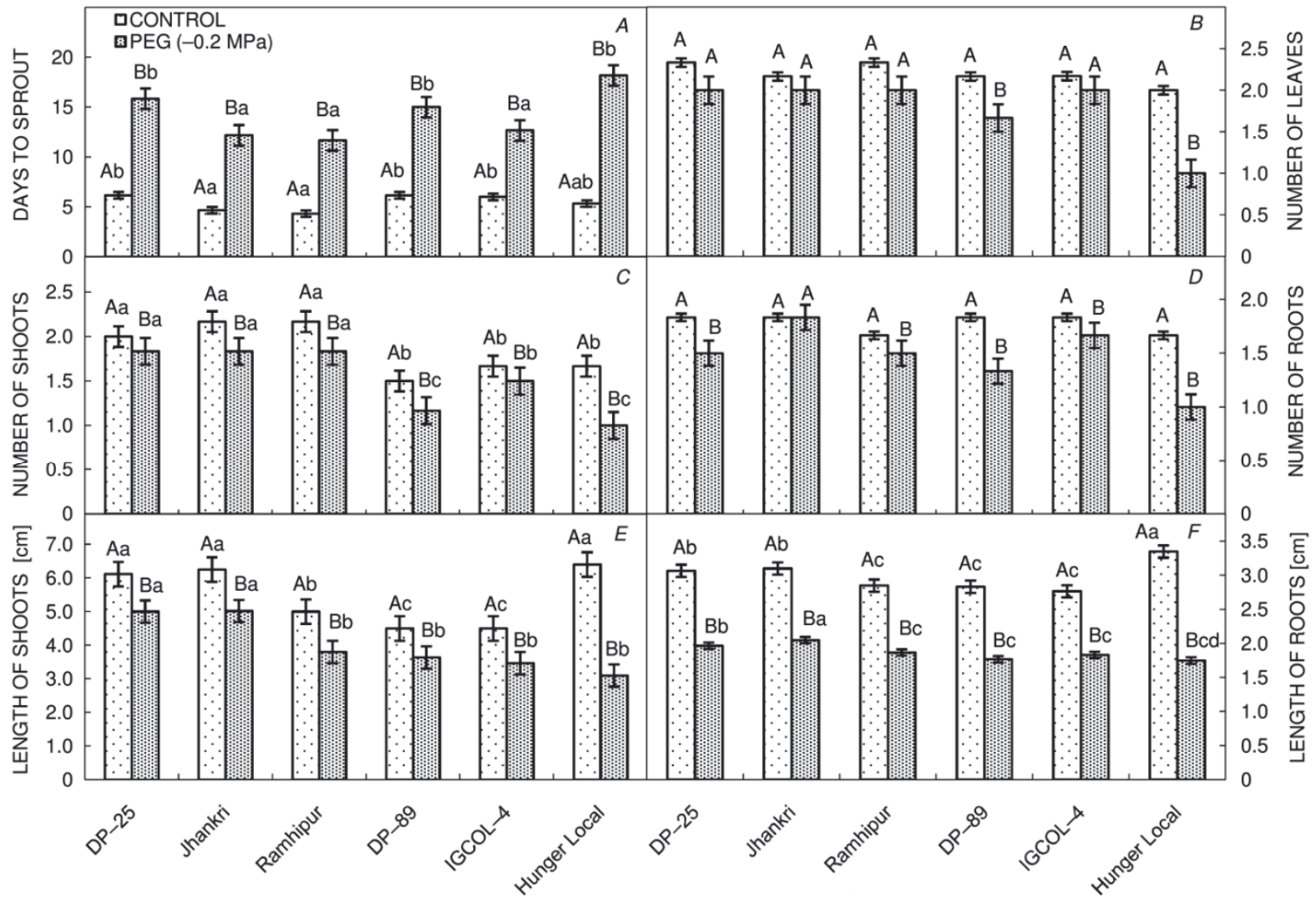

GENOTYPE

Fig. 1. Effect of in vitro PEG-mediated osmotic stress on a growth response of taro genotypes. $A$-days to sprout; $B$ - number of leaves; $C$ - number of shoots; $D$ - number of roots; $E$ - length of shoots, and $F$ - length of roots. Values are the mean of six replicates and bars represent standard error of means. Different letters in uppercase represent significant differences between the treatments (control and $-0.2 \mathrm{MPa}$ ) in the genotypes and lowercase represents significant difference between the genotypes under each treatment according to Tukey's test.

Table 2. Two-way analysis of variance (mean sum of squares) for morpho-physiological and biochemical properties of taro genotypes under in vivo PEG-mediated osmotic stress conditions in a $6 \times 2$ factorial experiment in a complete randomised design (CRD). *,**and NS $-P \leq 0.05, P \leq 0.01$, and $P>0.05$, respectively.

\begin{tabular}{lllll}
\hline Source & Genotype & PEG & Genotype $\times$ PEG & Error \\
\hline$D f$ & 5 & 1 & 5 & 24 \\
Leaf area & $7792.27^{* *}$ & $2414.55^{* *}$ & $410.26^{* *}$ & 84.87 \\
Relative water content (RWC) & $65.81^{* *}$ & $657.60^{* *}$ & $85.39^{* *}$ & 5.10 \\
Chlorophyll stability index (CSI) & $89.22^{* *}$ & $873.41^{* *}$ & $57.14^{* *}$ & 11.67 \\
Photosynthetic rate $\left(P_{\mathrm{N}}\right)$ & $10.34^{* *}$ & $71.01^{* *}$ & $5.00^{*}$ & 1.50 \\
Transpiration rate $(E)$ & $1.88^{* *}$ & $0.91^{*}$ & $0.03^{\mathrm{NS}}$ & 0.20 \\
Stomatal conductance $\left(g_{\mathrm{s}}\right)$ & $400.08^{* *}$ & $929.03^{* *}$ & $133.86^{* *}$ & 27.28 \\
Stomatal resistance $\left(R_{\mathrm{s}}\right)$ & $0.0005^{* *}$ & $0.0005^{*}$ & $0.0001^{\mathrm{NS}}$ & 0.0001 \\
Intercellular CO concentration $\left(C_{\mathrm{i}}\right)$ & $12075.86^{* *}$ & $27914.61^{* *}$ & $398.97^{*}$ & 149.99 \\
Carboxylation efficiency $(\mathrm{CE})$ & $0.00037^{* *}$ & $0.00038^{* *}$ & $0.00012^{*}$ & 0.00004 \\
Transpiration efficiency (TE) & $12.82^{* *}$ & $12.63^{* *}$ & $5.73^{*}$ & 1.61 \\
Total soluble protein content & $1012.38^{* *}$ & $468.36^{* *}$ & $38.45^{* *}$ & 1.36 \\
Proline content & $165.05^{* *}$ & $354.90^{* *}$ & $21.87^{* *}$ & 2.12 \\
Total soluble sugar (TSS) & $59.85^{* *}$ & $108.64^{* *}$ & $22.44^{* *}$ & 1.00 \\
Reducing sugar $(\mathrm{RS})$ & $16.74^{* *}$ & $22.58^{* *}$ & $2.64^{* *}$ & 0.32 \\
Superoxide dismutase (SOD) & $3806.19^{* *}$ & $52227.48^{* *}$ & $993.73^{* *}$ & 0.52 \\
Guaiacol peroxidase $(\mathrm{GPX})$ & $0.00341^{* *}$ & $0.05549^{* *}$ & $0.00138^{* *}$ & 0.00003 \\
Phenol content & $0.06^{* *}$ & $1.09^{* *}$ & $0.04^{* *}$ & 0.01 \\
Yield & $322.75^{* *}$ & $5236.93^{* *}$ & $186.50^{* *}$ & 43.61 \\
\hline
\end{tabular}


between 96.1 (IGCOL-4) to 98.5\% (Jhankri), while under the PEG stress, it was between 78.0 (Hunger Local) to 94.5\% (DP-89) (Fig. 2B). Percent decrease in RWC was more pronounced in leaves of Hunger Local (19.2\%) and it was the lowest in DP-89 (1.8\%). Similarly, CSI in leaves under control varied from 92.29 (IGCOL-4) to 99.05
(DP-25); it was reduced to 72.16 (Hunger Local)-88.98 (Ramhipur) under stress (Fig. 2C). Higher reduction in CSI was recorded in Hunger Local $(22.4 \%)$ as compared to other genotypes IGCOL-4, Ramhipur, DP-89, Jhankri, and DP-25, where the rate of decrease in CSI was in the range of $4.6-11.8 \%$.

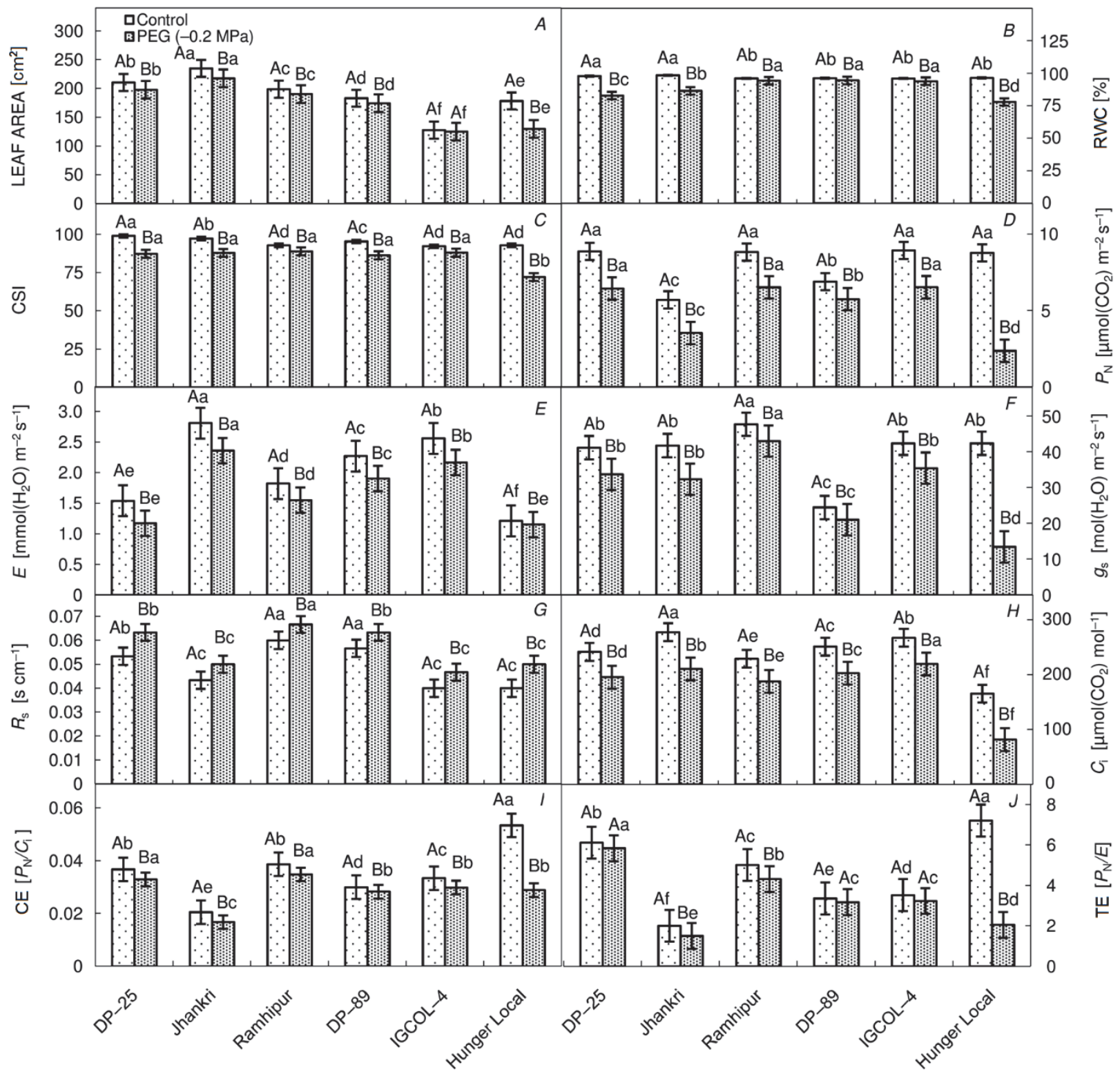

GENOTYPE

Fig. 2. Morphological and physiological properties of taro genotypes as influenced by PEG-mediated osmotic stress conditions. $A-$ leaf area; $B$ - relative water content $(\mathrm{RWC}) ; C$ - chlorophyll stability index $(\mathrm{CSI}) ; D$ - photosynthetic rate $(P \mathrm{~N}) ; E-$ transpiration rate $(E)$; $F$ - stomatal conductance $\left(g_{\mathrm{s}}\right) ; G$ - stomatal resistance $\left(R_{\mathrm{s}}\right) ; H$ - intercellular $\mathrm{CO}_{2}$ concentration $\left(C_{\mathrm{i}}\right) ; I-$ carboxylation efficiency $(\mathrm{CE}$, $\left.P_{\mathrm{N}} / C_{\mathrm{i}}\right) ; J$ - transpiration efficiency (TE, $P_{\mathrm{N}} / E$ ). Values are the mean of three replicates and bars represent standard error of means. Different letters in uppercase represent significant differences between the treatments (control and $-0.2 \mathrm{MPa}$ ) in the genotypes and lowercase represents significant difference between the genotypes under each treatment according to Tukey's test.

Effect of PEG on photosynthetic measurements of taro genotypes in vivo: The photosynthetic rate $\left(P_{\mathrm{N}}\right)$ significantly declined in all the studied genotypes under moisture stress as compared with control (Fig. 2D). The extent of reduction in $P_{\mathrm{N}}$ under PEG stress in comparison to control was lower in DP-89 (16.6\%), Ramhipur 
(26.1\%), IGCOL-4 (27.0\%), DP-25 (27.4\%), and Jhankri $(38.2 \%)$, whereas, the same was more pronounced in Hunger Local $(73.0 \%)$. The $E$ was recorded as $1.21-$ $2.81 \mathrm{mmol}\left(\mathrm{H}_{2} \mathrm{O}\right) \mathrm{m}^{-2} \mathrm{~s}^{-1}$ in control plants and reduced to 1.15-2.36 mmol $\left(\mathrm{H}_{2} \mathrm{O}\right) \mathrm{m}^{-2} \mathrm{~s}^{-1}$ under stress (Fig. 2E). Reduction in $E$ was higher in DP-25 (23.8\%) followed by DP-89 (16.2\%), Jhankri (16.0\%), IGCOL-4 (15.4\%), Ramhipur (14.9\%), and lower in Hunger Local (4.95\%).

Similarly, PEG-mediated osmotic stress resulted in the reduction of stomatal conductance $\left(g_{\mathrm{s}}\right)$ in all six genotypes studied (Fig. 2F). However, percent reduction was more pronounced in Hunger Local $(68.3 \%)$, whereas it was lesser in the genotypes Ramhipur (9.9\%), DP-89 (14.0\%), and IGCOL $-4(16.4 \%)$. The studied genotypes registered an increase in $R_{\mathrm{s}}$ under osmotic stress, while compared with control (Fig. $2 G$ ), the rate of increase in $R_{\mathrm{s}}$ was lower in Ramhipur (11.8\%) and DP-89 (11.8\%) and higher in Hunger Local $(25.0 \%)$. A significant decrease in internal $\mathrm{CO}_{2}$ concentration $\left(C_{\mathrm{i}}\right)$ was observed across the genotypes due to osmotic stress as compared with control (Fig. $2 H$ ). The rate of decrease was lower in resistant genotypes and higher in Hunger Local. CE and TE were adversely affected in the taro plants under PEG-mediated osmotic stress. Hunger Local showed a higher degree of reduction in the CE and TE (Fig. 2I,J).

Effect of PEG on biochemical properties of taro genotypes in vivo: Changes in total soluble proteins, as influenced by osmotic stress, is presented in Fig. $3 A$. Total soluble protein content in leaf tissue of taro genotypes under stress-free control was 31.32 (Hunger Local) to $58.15 \mathrm{mg} \mathrm{g}^{-1}(\mathrm{FM})$ (DP-25), which decreased to 15.57 (Hunger Local)-50.13 mg g g $^{-1}$ FM) (DP-25) under PEGmediated osmotic stress (Fig. $3 A$ ). Percent reduction in protein content was remarkably higher in Hunger Local $(50.3 \%)$ in comparison to the tolerant to moderately tolerant genotypes which ranged between 6.6 (DP-89)$16.8 \%$ (Jhankri).

On the contrary, the proline content increased under PEG stress in the genotypes investigated (Fig. $3 B$ ). The genotypes DP-89 and DP-25 accumulated more proline ( 70 and $77.8 \%$, respectively) in their leaf tissue, whereas Hunger Local showed only $6.3 \%$ increase in the proline content under osmotic stress.

Total soluble sugar (TSS) and reducing sugar (RS) content in the leaf tissues of taro genotypes were reduced significantly under moisture stress. IGCOL-4 and DP-25 exhibited lower variations in TSS (Fig. 3C) and RS

\section{Discussion}

We studied the growth responses, water relations, photosynthesis, accumulation of proline, and antioxidative systems in six genotypes of taro under in vitro and in vivo PEG-6000-mediated osmotic stress conditions. PEG of high molecular mass acts as a nonpenetrating osmotic
(Fig. 3D) content, whereas Hunger Local showed higher reduction under moisture stress compared with control.

Effect of PEG on antioxidative enzyme activities of taro genotypes in vivo: Leaf SOD activity was 69.77 (Hunger Local)-106.67 unit $\mathrm{mg}^{-1}$ (protein) (DP-89) under the stress-free conditions and 95.20 (Hunger Local)-202.27 unit $\mathrm{mg}^{-1}$ (protein) (DP-25) under osmotic stress $(-0.2 \mathrm{MPa})$ [Fig. 3E]. The PEG-induced SOD activity was more conspicuous in IGCOL-4 (96.3\%), DP-25 (93.7\%), and Ramhipur (90.9\%) than that in Hunger Local (36.5\%). The isozyme profiles under PEG stress revealed that both the cathodal and anodal isoforms of SOD were visible in all the genotypes, however, the intensity of bands of DP-89 were more prominent compared to other genotypes (Fig. 3E). A similar trend was observed for GPX activity, which also increased significantly in all the tested genotypes under stress conditions (Fig. $3 F$ ). GPX under control condition was in the range of 0.10 (Jhankri and Hunger Local)-0.15 (IGCOL-4) unit $\mathrm{mg}^{-1}$ (protein), while the activity was 0.15 (Hunger Local)-0.25 (DP-25) unit $\mathrm{mg}^{-1}$ (protein) under stress. Zymogram of GPX also exhibited a faint band, however, intensity of band was comparatively prominent in Ramhipur and DP-25 (Fig. $3 F$ ).

A significant accumulation of total phenols was observed in leaf tissues of taro genotypes under stress conditions (Fig. 3G). The increase in the phenol content was higher in DP-89 (43.1\%) followed by Jhankri (35.7\%), IGCOL-4 (32.8\%), and DP-25 (26.5\%). Hunger Local $(9.0 \%)$ and Ramhipur $(9.3 \%)$ showed the lower accumulation of phenols under moisture stress.

Yield: Corm yield of taro genotypes decreased under moisture stress compared with control (Fig. $3 H$ ). The rate of decrease in corm yield was in the range of 15.0-16.2\% in tolerant genotypes (IGCOL-4, Ramhipur, and DP-89), moderate $(20.3 \%$ and $21.5 \%$, in DP-25 and Jhankri, respectively), and higher in Hunger Local (41.4\%). Yield reduction was significantly and strongly positively correlated with leaf area $(r=0.994)$, CSI $(r=0.950), P_{\mathrm{N}}(r=$ $0.968), g_{\mathrm{s}}(\mathrm{r}=0.986), C_{\mathrm{i}}(r=0.987), \mathrm{CE}(r=0.978), \mathrm{TE}$ $(r=0.960)$, protein $(r=0.984)$, TSS $(r=0.924), \mathrm{RS}$ $(r=0.998)$, and inversely correlated with SOD $(r=$ -0.919 ) (Table 3). Based on the results of morphological and physiological changes, photosynthetic variations and biochemical properties, the pattern of osmotic stress tolerance in the tested genotypes of taro was in order of DP-89> IGCOL $-4>$ Ramhipur $>$ DP-25 $>$ Jhankri $>$ Hunger Local.

agent, lowering the water potential in the media, and thereby, it is widely used in osmotic-stress tolerance studies in plants (Albiski et al. 2012). The first and foremost detrimental effect of PEG in the shoot proliferation media was evident by delayed sprouting of the 
cormel tip explants followed by gradual growth retardation in the tested genotypes. Under in vitro PEG stress, early bud break was observed in Ramhipur, followed by Jhankri and IGCOL -4 . The shoot proliferation in term of a number of leaves, number of shoots, length of shoot and rooting was highly affected due to PEG as compared with the control. Under PEG-stress conditions, Hunger Local showed higher retardation up to $50 \%$ in shoot proliferation and rooting, which reflected its susceptibility towards PEG-mediated osmotic stress. IGCOL-4, DP-25, Jhankri, and Ramhipur showed an indication of tolerance towards PEG stress by maintaining the growth in vitro. Reports have shown that limited water availability results in reduced plant growth due to impairment of cell division and expansion (Hussain et al. 2008). Early sprouting with higher growth maintenance under PEG medium showed early indication towards moisture stress (Sahoo et al. 2006b).

The inherent ability of a plant to tolerate drought stress conditions is reciprocated by its ability to acclimatize under in vivo conditions (Anjum et al. 2011). As a drought avoidance strategy, plants are associated with the longterm morphological adjustment under stress through a reduction in plant size and leaf area (Levitt 1980).

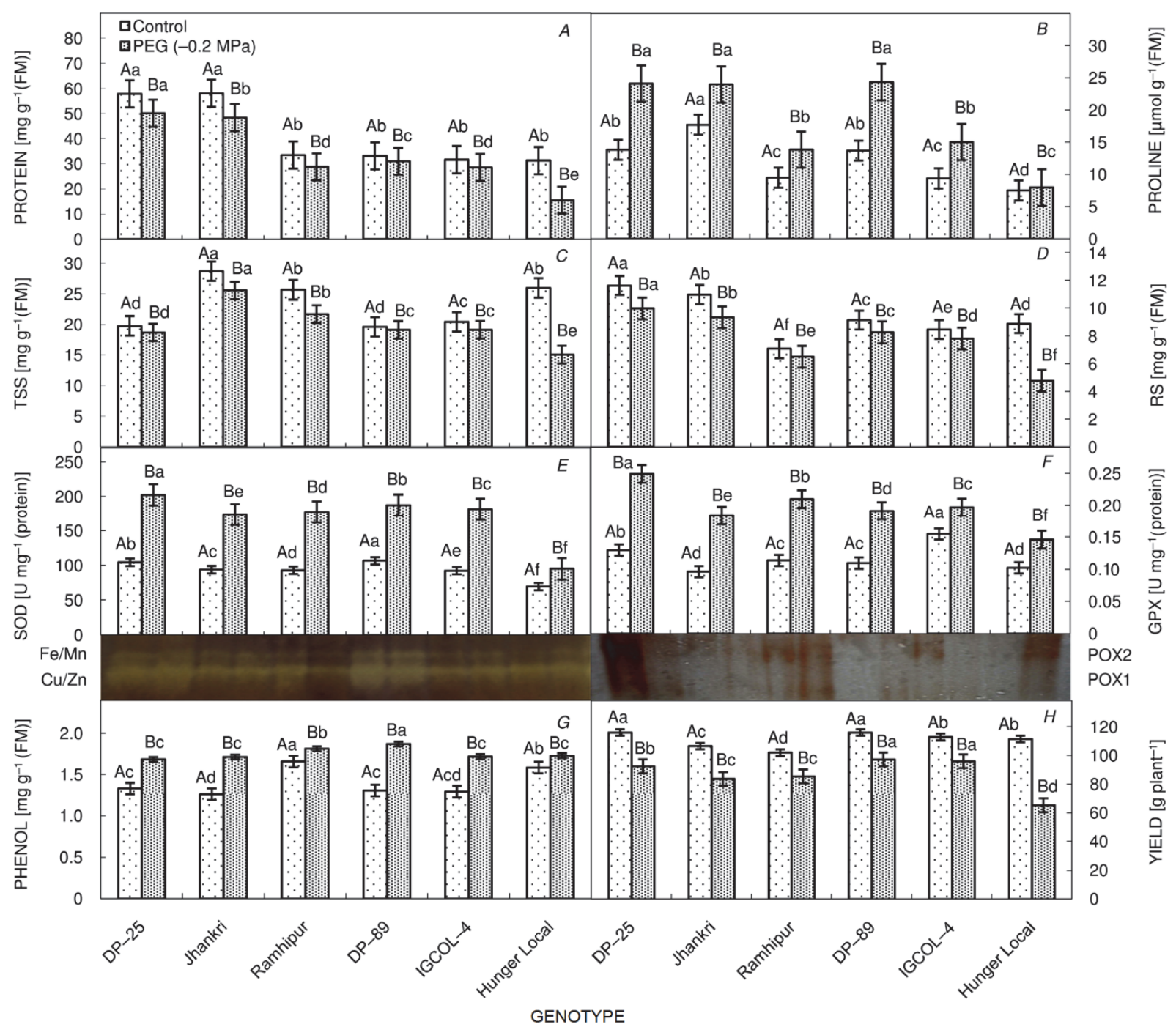

Fig. 3. Biochemical properties and yield of taro genotypes as influenced by PEG-mediated osmotic stress conditions. $A$ - total soluble protein content; $B$ - proline content; $C$ - total soluble sugar (TSS); $D$ - reducing sugar (RS); $E$ - superoxide dismutase (SOD); $F$ guaiacol peroxidase (GPX); $G$ - phenol content; $H$-yield. Values are the mean of three replicates and bars represent standard error of means. Different letters in uppercase represent significant differences between the treatments (control and $-0.2 \mathrm{MPa}$ ) in the genotypes and lowercase represents significant difference between the genotypes under each treatment according to Tukey's test. 
Table 3. Correlation coefficient ( $r$ value) between yield and photosynthetic, physiological, and biochemical properties of taro genotypes under in vivo PEG-mediated osmotic stress conditions. ${ }^{*},{ }^{* *}$ and ${ }^{\mathrm{NS}}-P \leq 0.05, P \leq 0.01$, and $P>0.05$, respectively.

\begin{tabular}{ll}
\hline Source & Yield \\
\hline Leaf area & $0.994^{* *}$ \\
Relative water content (RWC) & $0.815^{*}$ \\
Chlorophyll stability index $(\mathrm{CSI})$ & $0.950^{* *}$ \\
Photosynthetic rate $\left(P_{\mathrm{N}}\right)$ & $0.968^{* *}$ \\
Transpiration rate $(E)$ & $-0.731^{*}$ \\
Stomatal conductance $\left(g_{\mathrm{s}}\right)$ & $0.986^{* *}$ \\
Stomatal resistance $\left(R_{\mathrm{s}}\right)$ & $0.863^{*}$ \\
Internal $\mathrm{CO}_{2}$ concentration $\left(C_{\mathrm{i}}\right)$ & $0.987^{* *}$ \\
Carboxylation efficiency $(\mathrm{CE})$ & $0.978^{* *}$ \\
Transpiration efficiency $(\mathrm{TE})$ & $0.960^{* *}$ \\
Total soluble protein content & $0.984^{* *}$ \\
Proline content & $-0.814^{*}$ \\
Total soluble sugar (TSS) & $0.924^{* *}$ \\
Reducing sugar $(\mathrm{RS})$ & $0.998^{* *}$ \\
Superoxide dismutase (SOD) & $-0.919^{* *}$ \\
Guaiacol peroxidase $(\mathrm{GPX})$ & $-0.286^{\mathrm{NS}}$ \\
Phenol content & $-0.546^{\mathrm{NS}}$ \\
\hline
\end{tabular}

Among the morphological traits, leaf area is adversely affected by drought stress and correlated with biomass production and yield (Blum 2009). Reduction in leaf surface area for transpiration is one of the earliest visible impacts of water stress, which was also evident in our study. All the studied genotypes showed a reduction in leaf area under stress conditions. Interestingly, we observed that IGCOL -4 attained lesser leaf area under both control and stress conditions, and it managed to cope up the stress with lesser reduction in the leaf area. However, the percent reduction in the leaf area of Ramhipur, DP-89, and DP-25 were similar with IGCOL-4. Our results are in accordance with the findings of Mabhaudhi and Modi (2015) who had demonstrated a higher leaf area index (LAI) for a taro landrace, which managed to avoid drought stress through reduced canopy growth.

The RWC of the plants is considered as a measure of plant water status, reflecting its metabolic activity in tissues and used as an important index for dehydration tolerance (Anjum et al. 2011). In our study, RWC was significantly reduced by the PEG stress in all studied taro genotypes with the highest percent reduction in Hunger Local and lower reduction was found in DP-89. The genotypes Ramhipur and IGCOL -4 also showed lesser reduction in RWC, which is correlated with the reduced leaf area that might contribute towards reducing plant water use.

Lower reduction in the $\mathrm{Chl}$ content is a strategy employed by the plants to remove excess radiation energy under limited water availability. In our study, we observed a significant decrease in CSI of taro leaves exposed to PEG-mediated osmotic stress. The genotypes Ramhipur and IGCOL -4 showed the lower decrease (4.2 and 4.6\%) in leaf CSI in comparison to Hunger Local (22.4\%). We have observed the similar results in a taro hybrid and its parents when imposed to PEG stress (Sahoo et al. 2006b). Mabhaudhi and Modi (2015) suggested that the Umbumbulu (UM) landrace of taro was able to downregulate its photosynthesis by decreasing $\mathrm{CO}_{2}$ availability and lowering CSI. Maintenance of lower variation in leaf area accompanied by minimum changes in RWC and CSI in Ramhipur, IGCOL -4 , and DP-89 could be one of the avoidance strategies adopted by these genotypes to cope with stress.

Our results under in vivo PEG-induced stress indicated that $P_{\mathrm{N}}, E$, and $g_{\mathrm{s}}$ declined in all the studied genotypes. The decreased $P_{\mathrm{N}}$ as a consequence of stomatal closure (Liu et al. 2005, Sourour et al. 2017) and leaf area reduction under water stress are the key contributors to a yield loss under drought (Legay et al. 2011). The reduction in $P_{\mathrm{N}}$ could occur due to the closure of stomata which resulted in a decrease in $g_{\mathrm{s}}$. Stomatal closure is a drought-avoidance mechanism which allows the plants to minimise transpiration water loss (Chaves et al. 2003). Stomatal closure also restricts the diffusion of $\mathrm{CO}_{2}$ into leaves, influences $g_{\mathrm{s}}$ and $R_{\mathrm{s}}$ (Tombesi et al. 2015) and thereby results in lower $C_{\mathrm{i}}$. In our study, the genotypes DP-89, IGCOL-4, and Ramhipur exhibited lesser reductions in $P_{\mathrm{N}}$ and $g_{\mathrm{s}}$, which could be helpful for maintaining better growth in terms of leaf area. The $E$ highly decreased in DP-25 and DP-89 in our study which was inversely correlated with $P_{\mathrm{N}}$. Reports have shown that $g_{\mathrm{s}}$ decreased in taro under moisture stress to minimize the rate of transpiration (Mabhaudhi et al. 2013). Based on our results, the genotypes DP-89, Ramhipur, and IGCOL-4 exhibited their credibility in terms of minimum fluctuation in $g_{\mathrm{s}}$ and $R_{\mathrm{s}}$ to maintain the $P_{\mathrm{N}}$ and $E$. A relatively stable $C_{\mathrm{i}}$ was registered by these genotypes which was influenced by uptake of atmospheric $\mathrm{CO}_{2}$ during the course of photosynthesis. In our investigation, DP-89, Ramhipur, and IGCOL -4 managed to maintain the CE and TE under moisture stress conditions in comparison to Hunger Local.

Moisture stress influences protein synthesis in leaves and the content of total soluble leaf proteins decreases under stress (Suseela et al. 2015). Decreased protein contents in response to moisture stress might be due to lowering of overall protein synthesis and/or increasing protein degradation (Singh 2003). We observed a significant reduction in the total soluble protein content under PEG-mediated osmotic stress, it was lower in DP-89, IGCOL-4, and Ramhipur in comparison to Hunger Local. In support of our results, there are studies showing that the total soluble proteins significantly decreased in the presence of PEG in other crops (Gharineh and Karmollachaab, 2013). The carbohydrate content such as TSS and RS also declined under osmotic stress; they were significantly lower in DP-89, DP-25, and IGCOL-4. The decrease in the carbohydrate content in stressed plants could be attributed to the reduction in photosynthetic rate 
as the later is considered to be the main source for the accumulation of soluble sugars.

Proline, an essential osmolyte (Kumar et al. 2011), plays a major role as an antioxidative defense molecule and a signaling molecule in plant systems under exposure to various stress conditions (Hayat et al. 2012). We observed an increase in the proline content under PEG stress in all the tested genotypes, remarkably higher in DP89, DP-25, and IGCOL-4. The elevated proline content under osmotic stress is proposed to maintain plant existence (Ghorbanli et al. 2012) by managing osmotic balance, preventing electrolyte leakage, and lowering concentrations of reactive oxygen species (ROS) to prevent oxidative burst in plants (Hayat et al. 2012). Increased synthesis of total phenolics in stressed plants also exhibited a protective mechanism against the cellular structures from oxidative damage (Chakraborty and Pradhan 2012). In our study, DP-89, Ramhipur, and IGCOL-4 showed the higher total phenol content, which was evidence of cellular adaptive mechanism towards scavenging ROS during stress.

Overproduction of ROS during stress is being scavenged by enzymatic and nonenzymatic antioxidants (Sahoo et al. 2007), which is one of the vital mechanisms of drought tolerance (Farooq et al. 2009). Induction of an efficient cellular antioxidant machinery is crucial for protecting plants against the adverse effects of abiotic stresses (Pérez-Clemente et al. 2013). In our study, SOD and GPX activities significantly increased under osmotic stress across the taro genotypes tested, however, the induction was higher in DP-25, DP-89, IGCOL-4, and Ramhipur as compared to Hunger Local and Jhankri, which is in accordance with the report of Khanna-Chopra and Selote (2007). For SOD, two isoforms were detected in the studied genotypes which could be compared with the reports of Gomez et al. (2004), who suggested anodal isoforms of SOD as $\mathrm{Cu} / \mathrm{Zn}$ and the cathodal isoform of SOD as Fe/Mn. The genotype DP-89 exhibited higher SOD activities with two prominent isoforms which were comparatively faint in Hunger Local. Similarly, DP-25 and Ramhipur showed higher GPX activities with two isoforms POX-1 and POX-2. Our results showed that SOD and GPX play major roles in taro leaves in scavenging of ROS during osmotic stress. Previously, we have also demonstrated a similar role of SOD (Fe/Mn and
$\mathrm{Cu} / \mathrm{Zn}$ ) and GPX (POX-1 and POX-2) in taro against biotic-stress tolerance (Sahoo et al. 2007).

The cumulative effect of morphological, physiological, and biochemical gestures under osmotic stress influences tuberization. Tolerant genotypes have the ability to maintain tuber yield under osmotic stress conditions and exhibit minimum yield reductions under scarce water conditions (Obidiegwu et al. 2015). Significant and strong correlation of photosynthetic parameters towards yield maintenance under osmotic stress showed its crucial role on source-sink relationship in taro. Balanced physiological and biochemical attributes with a strong enzymatic antioxidative system resulted in the low yield reduction in studied genotypes. We experienced a lower yield $(<20 \%)$ reduction in IGCOL-4, DP-89, and Ramhipur; they showed their ability to maintain the yield stability under harsh environments and proved themselves as tolerant. However, Hunger Local exhibited $41.4 \%$ of yield loss under osmotic stress which reflects its susceptibility towards the imposed stress.

Conclusion: In summary, we observed that all the studied taro genotypes exhibited various degrees of avoidance and tolerance mechanisms under in vitro and in vivo PEGmediated osmotic stress conditions at morphological, physiological, and biochemical level. However, the genotypes Ramhipur, IGCOL-4, and DP-89 performed better growth in vitro and showed a moderate decrease in leaf area and RWC under stress suggesting that they were able to strike a balance between minimum water loss through transpiration while allowing biomass production to continue. This was consistent with their degree of stomatal control accompanied with the lesser decrease in CSI and RWC. In vitro PEG studies could be used as a reliable technique for the quick and efficient screening studies as short in vitro osmotic shock at cellular level triggers longterm events to combat stress. Higher photosynthesis and RWC of leaf tissues at crucial tuberization period under stress is coupled with yield maintenance in taro. Enzymatic antioxidants, SOD and GPX in particular, could be an important biochemical indicator for stress tolerance in taro. The genotypes DP-89, IGCOL-4, and Ramhipur showed the inherent tolerance traits towards osmotic stress and could be used as source materials in the future breeding program in taro.

\section{References}

Albiski F., Najla S., Sanoubar R. et al.: In vitro screening of potato lines for drought tolerance. - Physiol. Mol. Biol. Plants 18: 315-321, 2012.

Anjum S.A., Xie X., Wang L. et al.: Morphological, physiological and biochemical responses of plants to drought stress. Afr. J. Agric. Res. 6: 2026-2032, 2011.

Bates L.S., Waldren R.P., Teare I.D.: Rapid determination of free proline for water stress studies. - Plant Soil 39: 205-207, 1973.

Biradar R.S., Venkateswaralu T., Hrishi N.: Leaf area estimation in Colocasia. - J. Root Crops. 4: 51-53, 1978.
Blum A.: Drought resistance, water-use efficiency, and yield potential - are they compatible, dissonant, or mutually exclusive? - Aust. J. Agric. Res. 56: 1159-1168, 2005.

Blum A.: Effective use of water (EUW) and not water-use efficiency (WUE) is the target of crop yield improvement under drought stress. - Field Crops Res. 112: 119-123, 2009.

Bradford M.M.: A rapid and sensitive method for the quantification of microgram quantities of proteins utilizing the principle of protein-dye binding. - Anal. Biochem. 72: 248-254, 1976. 
Chakraborty U., Pradhan B.: Oxidative stress in five wheat varieties (Triticum aestivum L.) exposed to water stress and study of their antioxidant enzyme defense system, water stress responsive metabolites and $\mathrm{H}_{2} \mathrm{O}_{2}$ accumulation. - Braz. J. Plant Physiol. 24: 117-130, 2012.

Chandra A., Pathak P.S., Bhatt R.K. et al.: Variation in drought tolerance of different Stylosanthes accessions. - Biol. Plantarum 48: 457-460, 2004.

Chaves M.M., Maroco J.P., Pereira J.S.: Understanding plant responses to drought - from genes to the whole plant. - Funct. Plant Biol. 30: 239-264, 2003

Chen K, Arora R.: Priming memory invokes seed stresstolerance. - Environ. Exp. Bot. 94: 33-45, 2013.

Chen K., Fessehaie A., Arora R.: Selection of reference genes for normalizing gene expression during seed priming and germination using qPCR in Zea mays and Spinacia oleracea. - Plant Mol. Biol. Rep. 30: 478-487, 2012.

Dasgupta M., Sahoo M.R., Kole P.C. et al.: Evaluation of orangefleshed sweet potato (Ipomoea batatas L.) genotypes for salt tolerance through shoot apex culture under in vitro $\mathrm{NaCl}$ mediated salinity stress conditions. - Plant Cell Tiss. Org. 94: 161,2008

Farooq M., Wahid A., Kobayashi N. et al.: Plant drought stress: effects, mechanisms and management. - Agron. Sustain. Dev. 29: 185-212, 2009.

Flexas J., Bota J., Escalona J.M. et al.: Effects of drought on photosynthesis in grapevines under field conditions: an evaluation of stomatal and mesophyll limitations. - Funct. Plant Biol. 29: 461-471, 2002.

Gharineh M.H., Karmollachaab A.: Effect of silicon on physiological characteristics wheat growth under water-deficit stress induced by PEG. - Int. J. Agron. Plant Prod. 4: 1543$1548,2013$.

Ghorbanli M., Gafarabad M., Amirkian T. et al.: Investigation of proline, total protein, chlorophyll, ascorbate and dehydroascorbate changes under drought stress in Akria and Mobil tomato cultivars. - Iran J. Plant Physiol. 3: 651-658, 2012.

Giannopolitis C.N., Ries S.K.: Superoxide dismutases. I. Occurrence in higher plants. - Plant Physiol. 59: 309-314, 1977.

Gill S.S., Tuteja N.: Reactive oxygen species and antioxidant machinery in abiotic stress tolerance in crop plants. - Plant Physiol. Bioch. 48: 909-930, 2010.

Gomez J.M., Jimenez A., Olmos E. et al.: Location and effects of long-term $\mathrm{NaCl}$ stress on superoxide dismutase and ascorbate peroxidase isoenzymes of pea (Pisum sativum $\mathrm{cv}$. Puget) chloroplasts. - J. Exp. Bot. 55: 119-130, 2004.

Hayat S., Hayat Q., Alyemeni M.N. et al.: Role of proline under changing environments. - Plant Signal Behav. 7: 1456-1466, 2012.

Hussain M., Malik M.A., Farooq M. et al.: Improving drought tolerance by exogenous application of glycinebetaine and salicylic acid in sunflower. - J. Agron. Crop Sci. 194: 193-199, 2008.

Khanna-Chopra R., Selote D.S.: Acclimation to drought stress generates oxidative stress tolerance in drought-resistant than susceptible wheat cultivar under field conditions. - Environ. Exp. Bot. 60: 276-283, 2007.

Kumar R.R., Karajol K., Naik G.R.: Effect of polyethylene glycol induced water stress on physiological and biochemical responses in Pigeonpea (Cajanus cajan L. Mill sp.). - Rec. Res. Sci. Technol. 3: 148-152, 2011.

Laemmli U.K.: Cleavage of structural proteins during the assembly of the head of bacteriophage T4. - Nature 227: 680$685,1970$.

Legay S., Lefèvre I., Lamoureux D. et al.: Carbohydrate metabolism and cell protection mechanisms differentiate drought tolerance and sensitivity in advanced potato clones (Solanum tuberosum L.). - Funct. Integr. Genomic. 11: 275291, 2011.

Levitt J.: Responses of Plants to Environmental Stresses, Vol. II. Water, Radiation, Salt and Others Stresses. Pp. 395-434. Academic Press, New York 1980.

Li X., Liu F.: Drought stress memory and drought stress tolerance in plants: biochemical and molecular basis. - In: Hossain M.A., Wani S.H., Bhattacharjee S. et al. (ed.): Drought Stress Tolerance in Plants, vol. 1. Physiology and Biochemistry. Pp. 17-44. Springer, Basel 2016.

Li X., Topbjerg H.B., Jiang D. et al.: Drought priming at vegetative stage improves the antioxidant capacity and photosynthesis performance of wheat exposed to a short-term low temperature stress at jointing stage. - Plant Soil 393: 307-318, 2015.

Liu F.L., Jensen C.R., Shahanzari A. et al.: ABA regulated stomatal control and photosynthetic water use efficiency of potato (Solanum tuberosum L.) during progressive soil drying. - Plant Sci. 168: 831-836, 2005.

Luo H.H., Zhang Y.L., Zhang W.F.: Effect of water stress and re watering on photosynthesis, root activity, and yield of cotton with drip irrigation under mulch. - Photosynthetica 54: 65-73, 2016.

Mabhaudhi T., Modi A.T., Beletse Y.G.: Response of taro (Colocasia esculenta L. Schott) landraces to varying water regimes under a rain shelter. - Agr. Water Manage. 121: 102$112,2013$.

Mabhaudhi T., Modi A.T.: Drought tolerance of selected South African taro (Colocasia esculents L. Schott) landraces. - Exp. Agr. 51: 451-466, 2015.

Mohan M.M., Narayanan S.L., Ibrahim S.M.: Chlorophyll stability index (CSI): its impact on salt tolerance in rice. - Int. Rice Res. Notes 25: 38-39, 2000.

Murashige T., Skoog F.: A revised medium for rapid growth and bioassay with tobacco tissue culture. - Physiol. Plantarum 15: 473-497, 1962

Muscolo A., Junker A., Klukas C. et al.: Phenotypic and metabolic responses to drought and salinity of four contrasting lentil accessions. - J. Exp. Bot. 66: 5467-5480, 2015.

Nelson N.: A photometric adaptation of the Somogyi's method for the determination of glucose. - J. Biol. Chem. 153: 375380, 1944.

Obidiegwu J.E., Bryan G.J., Jones H.G. et al.: Coping with drought: stress and adaptive responses in potato and perspectives for improvement. - Front. Plant Sci. 6: 542, 2015.

Perez N.C.M., Espinosa R.G., Castaneda C.L. et al.: Water relations, histopathology and growth of common bean (Phaseolus vulgaris L.) during pathogenesis of Macrophomina phaseolina under drought stress. - Physiol. Mol. Plant P. 60: 185-195, 2002

Pérez-Clemente R.M., Vives V., Zandalinas S.I. et al.: Biotechnological approaches to study plant responses to stress. - Biomed. Res. Int. 2013: 654120, 2013.

Ramírez D.A., Rolando J.L., Yactayo W. et al.: Improving potato drought tolerance through the induction of long-term water stress memory. - Plant Sci. 238: 26-32, 2015.

Ravi V., Chowdhury S.R.: Physiological response of taro to moisture stress. - J. Root Crops 23: 63-66, 1997. 
Roe J.H.: The determination of sugar in blood and spinal fluid with anthrone reagent. - J. Biol. Chem. 212: 335-343, 1955.

Sahoo M.R., Dasgupta M., Kole P.C. et al.: Antioxidative enzymes and isoenzymes analysis of taro genotypes and their implications in Phytophthora blight disease resistance. Mycopathologia 163: 241-248, 2007.

Sahoo M.R., Dasgupta M., Mukherjee A.: Effect of in vitro and in vivo induction of polyethylene glycol-mediated osmotic stress on hybrid taro (Colocasia esculenta L. Schott.). - Ann. Trop. Res. 28: 1-11, 2006 b.

Sahoo M.R., Kole P.C., Dasgupta M. et al.: Screening and selection of Colocasia for leaf blight, drought and salinity. Curr. Agr. Res. 19: 14-19, 2006a.

Singh D.P.: Water Deficit Stress in Stress Physiology. Pp. 64-79. New Age Publishers, New Delhi 2003.

Sourour A., Afef O., Mounir R. et al.: A review: morphological, physiological, biochemical and molecular plant responses to water deficit stress. - Int. J. Eng. Sci. 6: 1-4, 2017.

Sunitha S., Ravi V., George J. et al.: Aroids and water relations: An overview. - J. Root Crops 39: 10-21, 2013.

Suseela V., Tharayil N., Xing B. et al.: Warming and drought differentially influence the production and resorption of elemental and metabolic nitrogen pools in Quercus rubra. Glob. Change Biol. 21: 4177-4195, 2015.

Tombesi S., Nardini A., Frioni T. et al.: Stomatal closure is induced by hydraulic signals and maintained by $\mathrm{ABA}$ in drought-stressed grapevine. - Sci. Rep. 5: 12449, 2015.

Tukey J.W.: Comparing individual means in the analysis of variance. - Biometrics 5: 99-114, 1949.

Urbanek H., Kuzniak-Gebarowska E., Herka K.: Elicitation of defense responses in bean leaves by Botrytis cinerea polygalacturonase. - Acta Physiol. Plant. 13: 43-50, 1991.

Wei L., Wang L., Yang Y. et al.: Abscisic acid enhances tolerance of wheat seedlings to drought and regulates transcript levels of genes encoding ascorbate-glutathione biosynthesis. Front. Plant Sci. 30: 458, 2015.

Yue B., Xue W., Xiong L. et al.: Genetic basis of drought resistance at reproductive stage in rice: separation of drought tolerance from drought avoidance. - Genetics 172: 1213-1228, 2006.

Zieslin N., Ben-Zaken R.: Peroxidase activity and presence of phenolic substances in peduncles of rose flowers. - Plant Physiol. Bioch. 31: 239-247, 1993. 